\title{
Aggregate Savings When Individual Income Varies*
}

\author{
Martin Flodén** \\ Stockholm School of Economics and CEPR \\ SSE/EFI Working Paper Series in Economics and Finance \\ No 591 \\ March, 2005
}

\begin{abstract}
This paper examines aggregate savings in a general equilibrium model where infinitely lived households face volatile (and possibly uncertain) income paths, hold a risk-free asset, and face a liquidity constraint. I first show that the equilibrium capital stock in an economy without uncertainty, but where individual income varies, can be larger than in an economy where each household's income is constant. When income is stochastic, the equilibrium capital stock is always larger than when income is constant. This additional capital accumulation has sometimes been interpreted as precautionary savings, but I demonstrate that it is mostly generated by permanent-income motives.
\end{abstract}

JEL classification: E21; D52; D90

Keywords: equilibrium interest rate; aggregate savings; precautionary saving; infinite horizon; general equilibrium

\footnotetext{
${ }^{*}$ I thank Lars Ljungqvist for valuable comments and discussions, and the Bank of Sweden Tercentenary Foundation for generous funding.

** Department of Economics, Stockholm School of Economics, Box 6501, SE-113 83 Stockholm, Sweden. martin.floden@hhs.se, ph: +46-8-7369263.
} 


\section{Introduction}

It is well known that the equilibrium interest rate equals the time discount rate in neoclassical economies where income is constant. This result follows immediately from the first-order condition for consumption. As a consequence, the aggregate capital stock is determined by the time discount factor and parameters in the production function. Huggett (1993) and Aiyagari (1994) demonstrate that this result does not hold in economies where aggregate income is constant but where idiosyncratic income is volatile and stochastic, and where insurance markets are incomplete. In such economies, the equilibrium interest rate is lower than the time discount rate and the capital stock is larger than in economies with constant income.

In this paper, I examine if the fall in the interest rate and the increase in the capital stock are generated by income uncertainty or income variability. I conclude that in general both uncertainty and variability contribute to these changes, and that the equilibrium interest rate does not typically equal the time discount rate in economies without uncertainty.

To be more specific, I analyze aggregate savings in a general equilibrium model populated by a large number of infinitely lived households that are subject to liquidity constraints and face idiosyncratic future income paths. Economies with and without uncertainty are examined. When there is uncertainty, future income is stochastic as in Aiyagari (1994). When there is no uncertainty, I assume that all households learn about their entire future income path in an initial period. These income paths are drawn from identical but independent ergodic income processes. Chamberlain and Wilson (2000) show that each household's consumption then converges to some finite level if the interest rate $r$ equals the time discount rate $\rho$. As an extension to that result I show that there is a smallest sustainable aggregate savings level in the limit. That is, if $r=\rho$, aggregate savings either converge to this smallest sustainable level or to some higher level, depending on the initial wealth distribution.

The production function associates every interest rate to an aggregate capital stock. The equilibrium interest rate will necessarily be lower than the time discount rate if the capital stock implied by $r=\rho$ is smaller than the smallest sustainable savings level. I show that standard parameter values imply that aggregate savings are much larger than the capital stock when $r=\rho$. The equilibrium interest rate is therefore lower than the time discount rate even if there is no income uncertainty.

This finding has consequences for how precautionary savings is interpreted in dynamic general equilibrium models. Precautionary savings is defined as the change in savings induced by uncertainty. Following Aiyagari (1994) a number of studies, most notably Huggett and Ospina (2001), measure aggregate precautionary savings as the difference between the equilibrium capital stock in an economy with income uncertainty and the capital stock implied by $r=\rho$. Huggett and Ospina note that for any interest rate that is lower than the time discount rate, $r<\rho$, liquidity constraints will bind for some households in the stationary equilibrium. They therefore conclude that there is aggregate precautionary saving if and only if liquidity constraints bind for some households in equilibrium. I demonstrate here that the equilibrium interest rate in an economy without uncertainty may be smaller than the time discount rate, and consequently that liquidity constraints may bind for some 
households in a stationary equilibrium without uncertainty. I suggest alternative measures that do not result in precautionary savings in deterministic economies.

The structure of the paper is as follows. In Section 2, I first examine a partial equilibrium setting where the interest rate equals the time discount rate, and I solve analytically for the long-run aggregate savings level in the economy without uncertainty. Then, using standard parameter values and productivity processes, I demonstrate that aggregate savings typically are higher than the capital stock when $r=\rho$. Next, I solve for the equilibrium interest rate and capital stock both for the economy with and without income uncertainty. The definition of aggregate precautionary savings is discussed in Section 3 where I also show that much of the capital accumulation in stochastic economies is generated by permanent-income motives rather than precautionary motives. ${ }^{1}$ Section 4 concludes.

\section{Aggregate Savings and the Interest Rate}

The economy is populated by a continuum of households of unit mass. Let $t$ denote time, $\rho>0$ the time discount rate, $c$ consumption, and $u$ the momentary utility function. Households maximize expected life-time utility,

$$
U=\sum_{t=0}^{\infty}(1+\rho)^{-t} u\left(c_{t}\right)
$$

subject to a given $a_{0}$, a liquidity constraint $a_{t+1} \geq 0$, and the budget constraint

$$
a_{t+1}=\left(1+r_{t}\right) a_{t}+w_{t} z_{t}-c_{t} .
$$

where $a_{t+1}$ denotes asset holdings at the end of period $t, r$ is the interest rate, $w$ is the wage rate, and $z_{t}$ is the household's allocation of efficiency units of labor at time $t$. These efficiency units of labor are generated by ergodic and identical but independent Markov chains with transition matrix $P$ for the states $Z=\left[\begin{array}{llll}\zeta_{1} & \zeta_{2} & \cdots & \zeta_{n}\end{array}\right]^{\prime}$ where $\zeta_{1}>0$ and $\zeta_{i+1}>\zeta_{i}$, and $Z$ is normalized so that its unconditional expectation equals unity. The elements $p_{i, j}$ of the transition matrix denote transition probabilities from productivity level $i$ to productivity level $j$. Initial productivity $z_{0}$ is drawn from the stationary distribution of the Markov chain.

Two informational assumptions will be contrasted. When there is income uncertainty, households know $z_{t}$ in the beginning of period $t$ and form expectations about future income based on the transition probabilities $P$. When there is no income uncertainty, households learn about their entire productivity path $\left\{z_{t}\right\}_{t=0}^{\infty}$ in the beginning of period $t=0$.

For future reference, let $\lambda$ denote the measure of households over the state space $S, \lambda$ : $S \rightarrow \mathbb{R}$. We will focus on economies where factor prices are constant. In the economy with income uncertainty, a household's state in the beginning of period $t$ is $s_{t}=\left(z_{t}, a_{t}\right)$.

\footnotetext{
${ }^{1}$ According to the permanent-income and life-cycle hypotheses, households save in periods with unusually high income. Since I model households without an explicit life cycle, I refer to saving and dissaving induced by such anticipated income fluctuations as generated by permanent-income motives.
} 
See Aiyagari (1994) for further details about the stochastic economy. In the deterministic economy, a household's state in the beginning of period $t$ is $s_{t}=\left(\left\{z_{s}\right\}_{s=t}^{\infty}, a_{t}\right)$. The state space for current and future productivity is thus $S=Z^{\infty} \times[0, \infty)$.

\subsection{When the Interest Rate Equals the Time Discount Rate}

Let us first analyze a partial equilibrium setting without uncertainty, where the interest rate is constant and equal to the time discount rate, $r=\rho$, and where the wage rate $w$ is constant. What happens to aggregate savings over time in this economy? In particular, which is the smallest aggregate savings level that the economy can converge to?

To minimize aggregate savings in the limit I assume that $a_{0}=0$ for all households. Let $c_{t}=c\left(s_{t}\right)$ denote the household's optimal consumption in state $s_{t}$, and let $W_{t}$ denote the net present value of income for a household at date $t$,

$$
W_{t}=\sum_{j=0}^{\infty}(1+r)^{-j} w z_{t+j} .
$$

Define $Y_{t, T}$ as the discounted value of labor income from date $t$ and $T$ periods ahead,

$$
Y_{t, T}=\sum_{s=t}^{t+T-1}(1+r)^{-(s-t)} w z_{s}
$$

and define $W_{T}$ to be the household's highest income sequence of length $T$,

$$
W_{T}=\sup _{t \geq 0} Y_{t, T}
$$

Define also $\bar{W}$ as the discounted value of receiving the maximum labor income $w \zeta_{n}$ in every period,

$$
\bar{W}=w \zeta_{n} \sum_{j=0}^{\infty}(1+r)^{-j}
$$

Lemma 1 shows that consumption converges to the same level for all households and that this level is the annuity value of $\bar{W}$. The proof assumes that the transition probability from any productivity state $j$ to the highest productivity state $n$ is strictly positive, i.e. $p_{j, n}>0$. The lemma holds as long as $p_{n, n}>0$ and $\zeta_{n}$ is in the absorbing $\operatorname{subset}(\mathrm{s})$ of $Z$, and modified versions of the lemma hold otherwise. ${ }^{2}$

Lemma 1 Assume that $p_{j, n}>0$ for all $j$. Then

$$
W_{T} \stackrel{a . s .}{\rightarrow} \bar{W}
$$

and

$$
c_{t} \stackrel{a . s .}{\rightarrow} \frac{r}{1+r} \bar{W}=w \zeta_{n} .
$$

\footnotetext{
${ }^{2}$ I let $\stackrel{a . s .}{\rightarrow}$ denote convergence almost surely, and $\stackrel{p}{\rightarrow}$ convergence in probability.
} 
Proof. We first show that $W_{T} \stackrel{p}{\rightarrow} \bar{W}$, i.e.

$$
\lim _{T \rightarrow \infty} \operatorname{Pr}\left(\left|\bar{W}-W_{T}\right|>\varepsilon\right)=0 \text { for every } \varepsilon>0 .
$$

Define

$$
\bar{W}_{k}=\sum_{i=0}^{k} \beta^{i} \zeta_{n}
$$

Note that $\bar{W}_{k} \rightarrow \bar{W}$. For every $\varepsilon>0$ we can therefore find a finite $k$ such that $\left|\bar{W}-\bar{W}_{k}\right|<$ $\varepsilon$. Since $\bar{W}>W_{T}$ by definition, it remains to show that for every $k$

$$
\lim _{T \rightarrow \infty} \operatorname{Pr}\left(W_{T} \geq \bar{W}_{k}\right)=1 .
$$

Let

$$
q_{t, k}= \begin{cases}0 & \text { if } z_{t}=z_{t+1}=\ldots=z_{t+k-1}=\zeta_{n} \\ 1 & \text { otherwise }\end{cases}
$$

Note that $W_{T+1} \geq W_{T}$ for all $T$ since $z_{t}>0$ for all $t$. Note also that $W_{T} \geq \bar{W}_{k}$ if $q_{t, k}=0$ for any $t$. Therefore,

$$
\lim _{T \rightarrow \infty} \operatorname{Pr}\left(W_{T} \geq \bar{W}_{k}\right) \geq \lim _{t \rightarrow \infty} \operatorname{Pr}\left(\prod_{i=0}^{t} q_{i, k}=0\right) .
$$

Consider $\hat{T}=m k$ for some integer $m>0$. Then for all $t \geq \hat{T}$,

$$
\begin{aligned}
\operatorname{Pr}\left(\prod_{i=0}^{t} q_{i, k}=0\right) & \geq \operatorname{Pr}\left(\prod_{i=0}^{\hat{T}} q_{i, k}=0\right) \geq \\
\operatorname{Pr}\left(\prod_{i=0}^{m} q_{i k, k}=0\right) & =1-\left(1-\pi^{k}\right)^{m+1}
\end{aligned}
$$

where $\pi=\min _{j} p_{j, n}$. Note that $\lim _{m \rightarrow \infty} 1-\left(1-\pi^{k}\right)^{m+1}=1$ since $\pi>0$. It follows that

$$
\lim _{t \rightarrow \infty} \operatorname{Pr}\left(\prod_{i=0}^{t} q_{i}=0\right)=1
$$

and consequently that $W_{T} \stackrel{p}{\rightarrow} \bar{W}$. Since $W_{T+1} \geq W_{T}$ for all $T$, it follows that $W_{T} \stackrel{a . s .}{\rightarrow} \bar{W}$ (Lukacs, 1975, p. 49).

Convergence of consumption, $c_{t} \stackrel{a . s .}{\rightarrow} \frac{r}{1+r} \bar{W}$, follows immediately from theorem 3 in Chamberlain and Wilson (2000) and chapter 16.3 in Ljungqvist and Sargent (2004).

We are interested in the limiting behavior of aggregate savings. Aggregate savings (or asset holdings) are defined as

$$
A_{t}=\int a_{t} \mathrm{~d} \lambda_{t}
$$


Note that the budget constraint (1) together with $\int z_{t} \mathrm{~d} \lambda_{t}=1$ implies that the law of motion for aggregate savings is

$$
A_{t+1}=(1+r) A_{t}+w-\int c_{t} \mathrm{~d} \lambda_{t} .
$$

Proposition 1 states that aggregate savings converge and provides an expression for the limiting value.

\section{Proposition 1}

$$
A_{t} \stackrel{a . s .}{\rightarrow} \frac{w\left(\zeta_{n}-1\right)}{r} .
$$

Proof. First note that $\lim _{t \rightarrow \infty} A_{t}$ exists since $\lim _{t \rightarrow \infty} c_{t}$ exists for each household (Chamberlain and Wilson, 2000, lemma 2). Let $\bar{A}=\lim _{t \rightarrow \infty} A_{t}$. From Lemma 1, we know that $\lim _{t \rightarrow \infty} \int c_{t} \mathrm{~d} \lambda_{t}=w \zeta_{n}$. Using this in (2) we have

$$
\bar{A}=(1+r) \bar{A}+w-w \zeta_{n} \Rightarrow \bar{A}=\frac{w\left(\zeta_{n}-1\right)}{r} .
$$

The Proposition assumes that initial asset holdings are zero for all households. It is straightforward to verify that $A_{t}$ converges to some $A^{*} \geq \bar{A}$ if some households initially have positive asset holdings. If $r$ is not constant but converges to $\rho$ over time, it is also straightforward to verify that if $A_{t}$ converges to some $A^{*}$ then $A^{*} \geq \bar{A}$. This implies that there is no stationary equilibrium with $r=\rho$ and $\int a \mathrm{~d} \lambda<\bar{A}$ in this economy.

\subsection{Is There an Equilibrium with $\mathrm{r}=\rho$ ?}

To examine whether an interest rate equal to the time discount rate can be supported as an equilibrium, assume that capital and labor are used as inputs in a Cobb Douglas production function,

$$
Y=K^{\theta} H^{1-\theta}
$$

where $\theta$ is the capital share, $K$ is the aggregate capital stock, and $H=\int z \mathrm{~d} \lambda$ is the aggregate labor supply in efficiency units. Since $\int z \mathrm{~d} \lambda=1$ we have $H=1$.

There is no uncertainty so competition ensures that factor prices are $r=\theta K^{\theta-1}-\delta$, and $w=(1-\theta) K^{\theta}$, where $\delta$ is the depreciation rate of capital. In a stationary equilibrium, total asset holdings must equal the size of the capital stock, $\int a \mathrm{~d} \lambda=K$ (see Aiyagari (1994) for further details on the stationary equilibrium).

The implied aggregate capital stock is

$$
K(r)=\left(\frac{\theta}{r+\delta}\right)^{\frac{1}{1-\theta}}
$$


Proposition 1 shows that a stationary equilibrium with $r=\rho$ cannot exist if $\bar{A}>K(\rho)$. Whether this is the case depends on parameter values. Let me consider a plausible parameterization of the model. Following Aiyagari (1994) I set the capital share to $\theta=0.36$, the time discount rate to $\rho=0.04$, and the depreciation rate of capital to $\delta=0.08$. This calibration implies that $K=5.57$ and $w=1.19$ when $r=\rho$.

To calculate $\bar{A}$, we must specify an income process. The Markov chain for productivity or efficiency units of labor approximates the autoregressive process

$$
\ln z_{t+1}=\gamma \ln z_{t}+\varepsilon_{t+1}
$$

where $\gamma$ is the persistence of the process and $\varepsilon \sim \mathrm{N}\left(0, \sigma^{2}\right)$. In life-cycle settings and controlling for permanent effects Hubbard et al. (1995) estimate $\gamma$ to be around 0.95 and $\sigma^{2}$ to be around 0.03, and Storesletten et al. (2000) estimate $\gamma$ to be around 0.98 and $\sigma^{2}$ to be around 0.02 in U.S. data. Estimates like these are often used to calibrate dynastic infinite-horizon models. The productivity process is then typically approximated by a discrete process or at least restricted so that productivity is bounded. Here, I use Tauchen's (1986) algorithm to approximate the productivity process by a finite Markov chain. When applying Tauchen's algorithm, the width of the productivity grid must be specified. The extreme grid points $\ln \zeta_{1}$ and $\ln \zeta_{n}$ are $\pm m$ times the unconditional standard deviation for $\ln z .^{3}$ Following Tauchen, I set $m=3$, but the choice of $m$ is important for the implied $\bar{A}$ since it directly affects the highest possible productivity level $\zeta_{n}$. Table 1 first shows the $\zeta_{n}$ and $\bar{A}$ that is implied by Hubbard et al.'s and Storesletten et al.'s productivity processes. ${ }^{4}$ We see that savings converge to $\bar{A}=97.4$ or some higher level with Hubbard et al.'s process and to even higher levels with Storesletten et al.'s process. So if the interest rate equaled the time discount rate savings would be much higher than the capital stock which is $K(\rho)=5.57$. The final row in Table 1 shows that even Aiyagari's baseline productivity process, which is much less persistent and volatile, implies that aggregate savings converge to a higher value than $K(\rho)$.

Table 1: Aggregate Savings when $r=\rho$

\begin{tabular}{cccr}
$\gamma$ & $\sigma^{2}$ & $\zeta_{n}$ & \multicolumn{1}{c}{$\bar{A}$} \\
\hline 0.98 & 0.020 & 5.74 & 140.6 \\
0.95 & 0.030 & 4.28 & 97.4 \\
0.60 & 0.013 & 1.52 & 15.3 \\
\hline
\end{tabular}

To understand the intuition behind Proposition 1 it may be useful to consider an approximate solution to the infinite horizon model. Consider an economy populated by $N$ households. In the first period each household has $a_{0}=0$ and draws a sequence $\left\{x_{t}\right\}_{t=0}^{T-1}$ from the Markov chain for productivity. This sequence is assumed to repeat indefinitely as the household's productivity, i.e. $z_{t}=x_{t \bmod T}$ for $t \geq 0$. For each household the discounted value of future income varies with $t \bmod T$, so there are $T$ different values for this discounted value to consider, and consumption converges to the annuity value of the max-

\footnotetext{
${ }^{3}$ More specifically, $\ln \hat{\zeta}_{n}=m \sigma\left(1-\gamma^{2}\right)^{-1 / 2}$ where $\hat{\zeta}$ is productivity before normalizing so that $\mathrm{E} \zeta=1$.

${ }^{4}$ When using Tauchen's algorithm I set $n=9$, but the value of $n$ has negligible impact on the results.
} 
imum of these values (see chapter 16.3 in Ljungqvist and Sargent, 2004). ${ }^{5}$ As $T$ increases, the probability increases that there is at least some sequence $\left\{x_{i}, x_{i+1}, \ldots, x_{i+s}\right\}$ with high productivity in $\left\{x_{t}\right\}$, and then the discounted value of future income at date $i$ will be high. Similarly, the probability that there is some sequence $\left\{x_{i}, x_{i+1}, \ldots, x_{i+s}\right\}$ with low productivity increases. A household's asset holdings vary between zero at the date when the future income is at its maximum and some value that is increasing in the difference between the highest and smallest value of future income. This difference increases as $T$ increases and consequently average asset holdings also increase.

Figure 1 shows simulated outcomes for the three productivity processes when $N=10,000$ households and $T$ varies from 20 to 100,000 time periods. ${ }^{6}$ With the two persistent and volatile processes, aggregate savings exceed $K(\rho)$ already when $T=70$. But convergence is slow. When productivity follows the most persistent process, aggregate savings are $A=137.2$ after 100,000 periods compared to the equilibrium value $\bar{A}=140.6$ (see Table 1 ), and we see that convergence is even slower when productivity is less persistent. With $\gamma=0.60$, aggregate savings are $A=4.8$ after 50,000 periods and $A=5.1$ after 100,000 periods, compared to the equilibrium value $\bar{A}=15.3 .^{7}$

Figure 1: Convergence of Aggregate Savings
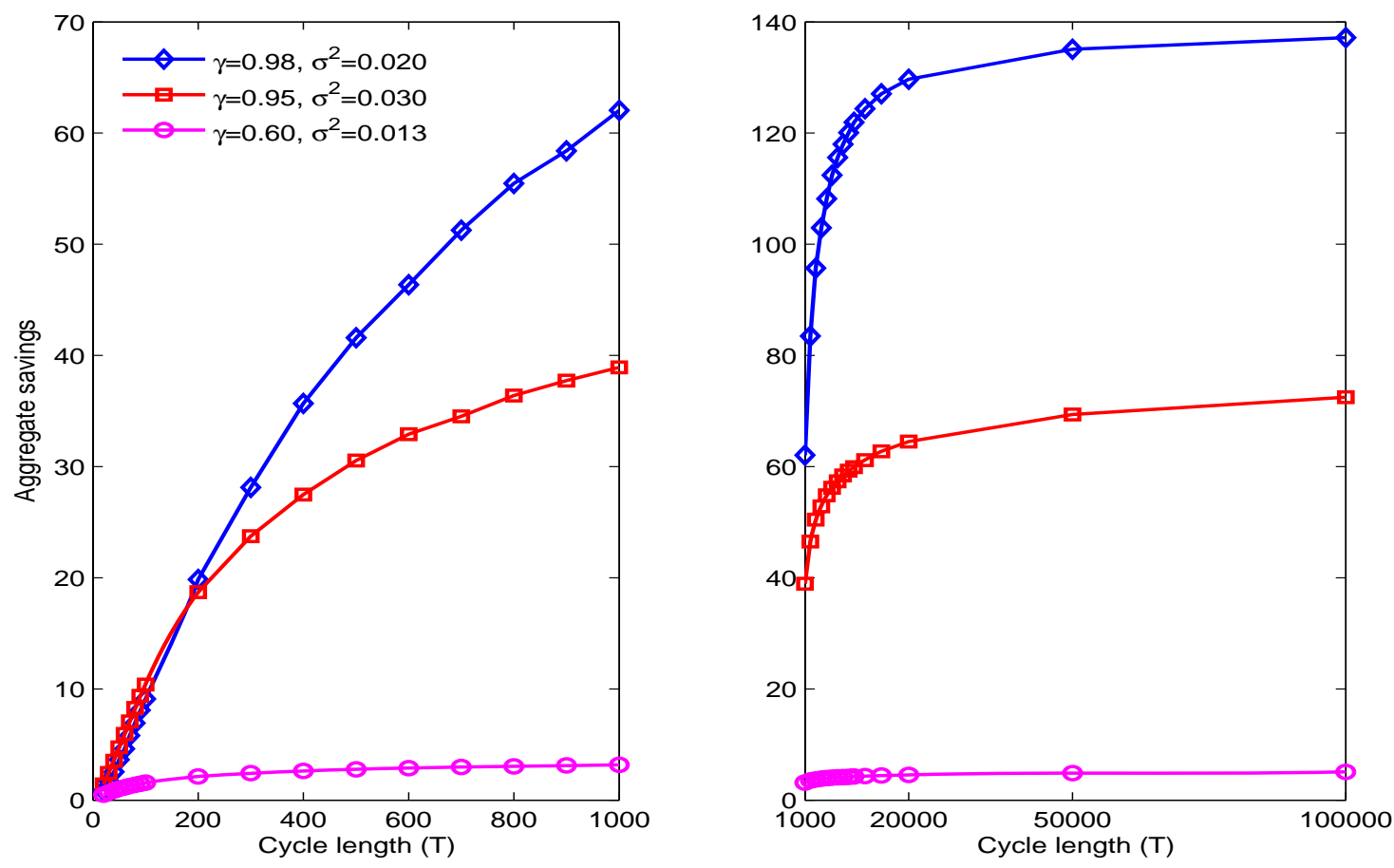

To summarize, we have seen theoretically that if income is sufficiently volatile, the amount of savings needed to sustain constant consumption paths is higher than the capital stock implied by $r=\rho$. We have also seen that this is not only a theoretical possibility but actually the outcome in realistically calibrated economies.

\footnotetext{
${ }^{5}$ In the present framework, consumption has converged for all households at date $T$.

${ }^{6}$ See the appendix for computational details.

${ }^{7}$ Aggregate savings equal $K(\rho)=5.57$ when $T \approx 500,000$ periods.
} 


\subsection{Equilibrium Interest Rate}

Let us now examine the equilibrium interest rate and capital stock when income follows one of the processes used above. To solve for the equilibrium when $r<\rho$, the utility function must be specified. Assume that it belongs to the constant relative risk aversion family,

$$
u(c)=\frac{c^{1-\mu}-1}{1-\mu}
$$

where $\mu$ is the degree of risk aversion. The equilibrium outcomes for $\mu \in\{1,3,5\}$ are reported in Table 2. The table reports results under three informational assumptions. When income is uncertain, households form expectations about future income conditional on their current income (as in Aiyagari, 1994), and when there is no income uncertainty, households learn about the entire income path in the first period. ${ }^{8}$ Under certainty equivalence, income follows the stochastic process, but households (incorrectly) think that income in any future period will equal the expected income in that period conditional on the household's current income, and households decide on current consumption and savings accordingly. I let $r^{*}, \bar{r}$, and $\hat{r}$ denote the equilibrium interest rates under these three informational assumptions.

The results in Table 2 show that the equilibrium interest rate in the deterministic economy, $\bar{r}$, can be substantially lower than the time discount rate (recall that $\rho=0.04$ ). In particular, this happens when the income process is volatile and when risk aversion is high. For the least persistent process, the equilibrium interest rate is close to the time discount rate even in the stochastic economy. The analysis above showed that the equilibrium interest rate in the deterministic economy is lower than the time discount rate, but also that finding this equilibrium interest rate is difficult in practice. The results behind Figure 1 showed that savings in the deterministic economy with $r=\rho$ does not exceed $K(\rho)$ until the time horizon is $T=500,000$ periods. And for any $\bar{r}<\rho$ aggregate savings will be lower. It turns out that the algorithm used for calculating $\bar{r}$ is too slow to be useful when $T$ is very high. ${ }^{9}$ Therefore, results for the deterministic economy under the least persistent income process are not reported in Table 2.

\footnotetext{
${ }^{8}$ See the Appendix for computational details.

${ }^{9}$ The algorithm, implemented in C, solves for the optimal consumption and asset path for one household in approximately 0.001 seconds, 2 seconds, and 2 minutes when $T=1,000, T=10,000$, and $T=100,000$, respectively.
} 
Table 2: Equilibrium Interest Rate and Aggregate Savings

\begin{tabular}{|c|c|c|c|c|c|c|c|c|}
\hline \multirow[b]{2}{*}{$\gamma$} & \multirow[b]{2}{*}{$\sigma^{2}$} & \multirow[b]{2}{*}{$\mu$} & \multicolumn{2}{|c|}{ uncertain income } & \multicolumn{2}{|c|}{ no uncertainty } & \multicolumn{2}{|c|}{ certainty equivalence } \\
\hline & & & $r^{*}$ & $K\left(r^{*}\right)$ & $\bar{r}$ & $K(\bar{r})$ & $\hat{r}$ & $K(\hat{r})$ \\
\hline \multirow[t]{3}{*}{0.98} & 0.020 & 1 & 0.0305 & 6.33 & 0.0315 & 6.25 & 0.0358 & 5.88 \\
\hline & & 3 & -0.0035 & 11.26 & 0.0148 & 8.05 & 0.0271 & 6.65 \\
\hline & & 5 & -0.0300 & 21.85 & -0.0006 & 10.61 & 0.0185 & 7.57 \\
\hline \multirow[t]{3}{*}{0.95} & 0.030 & 1 & 0.0280 & 6.56 & 0.0318 & 6.22 & 0.0343 & 6.01 \\
\hline & & 3 & -0.0013 & 10.76 & 0.0175 & 7.70 & 0.0246 & 6.89 \\
\hline & & 5 & -0.0205 & 16.66 & 0.0060 & 8.98 & 0.0177 & 7.67 \\
\hline \multirow[t]{3}{*}{0.60} & 0.013 & 1 & 0.0397 & 5.59 & n.s. & n.s. & 0.0399 & 5.57 \\
\hline & & 3 & 0.0388 & 5.65 & n.s. & n.s. & 0.0397 & 5.58 \\
\hline & & 5 & 0.0377 & 5.74 & n.s. & n.s. & 0.0396 & 5.60 \\
\hline
\end{tabular}

Note: n.s. indicates that no numerical solution was found.

\section{Precautionary Savings}

According to Leland (p. 465), "the 'precautionary' demand for saving usually is described as the extra saving caused by future income being random rather than determinate", and Sandmo (p. 358) argues that his result can be applied on households with income that is volatile ex post, only if ex post volatility goes hand in hand with ex ante uncertainty. Huggett and Ospina (2001, p. 375) say that "there is (positive) aggregate precautionary savings provided that the steady-state capital stock is larger in the presence than in the absence of idiosyncratic labor endowment uncertainty".

These definitions are not controversial. But implementing such definitions in a dynamic framework may be problematic since "the absence of uncertainty" is not uniquely defined. In practice, Huggett and Ospina (p. 381) interpret the absence of uncertainty as all households being endowed with the same constant labor efficiency. Huggett and Ospina measure precautionary savings as $K\left(r^{*}\right)-K(\rho)$, i.e. as the difference between the capital stock in an economy with stochastic income and the capital stock when income is constant. Using that definition of precautionary savings, they also prove that there is positive precautionary savings if and only if borrowing constraints bind for some households in the stationary equilibrium. Before discussing their results further, I summarize their analysis.

Consider stationary equilibria where the measure of households across the asset-income states is time invariant. If the borrowing constraint never binds for any household in equilibrium, the first order condition implies that

$$
u_{c}\left(c_{t}\right)=\frac{1+r}{1+\rho} \mathrm{E}_{t} u_{c}\left(c_{t+1}\right)
$$

for all households. Integrating over all households and noting that the expectations operator can be eliminated by using the law of large numbers and the time-invariance of $\lambda$, we 
get

$$
\int u_{c}\left(c_{t}\right) \mathrm{d} \lambda=\frac{1+r}{1+\rho} \int u_{c}\left(c_{t+1}\right) \mathrm{d} \lambda .
$$

Again, since $\lambda$ is time invariant, $\int u_{c}\left(c_{t}\right) \mathrm{d} \lambda=\int u_{c}\left(c_{t+1}\right) \mathrm{d} \lambda$ so we get $r=\rho$. This shows that the capital stock is the same as in a deterministic representative-agent economy as long as the borrowing constraint never binds.

Consider now the case where the borrowing constraint binds for some households in the stationary equilibrium. For these households the first order condition implies that

$$
u_{c}\left(c_{t}\right)>\frac{1+r}{1+\rho} \mathrm{E}_{t} u_{c}\left(c_{t+1}\right)
$$

while the first order condition still holds with equality for the other households. Now integrating over all households leads to

$$
\int u_{c}\left(c_{t}\right) \mathrm{d} \lambda>\frac{1+r}{1+\rho} \int u_{c}\left(c_{t+1}\right) \mathrm{d} \lambda .
$$

But the stationarity of the equilibrium still requires that $\int u_{c}\left(c_{t}\right) \mathrm{d} \lambda=\int u_{c}\left(c_{t+1}\right) \mathrm{d} \lambda$, so (3) implies that $r<\rho$. This is Huggett and Ospina's (2001) main result; the equilibrium capital stock $K(r)$ is higher than in the deterministic representative-agent economy if and only if the borrowing constraint binds for some households.

Recall that $\bar{r}$ denotes the interest rate in the stationary equilibrium of the perfect foresight economy. As we have seen, it is possible that $\bar{r}<\rho$ and consequently that the equilibrium capital stock is larger than $K(\rho)$ in economies without uncertainty. That the capital stock is higher than what is implied by $r=\rho$ is then a result of income being volatile rather than uncertain. If the equilibrium capital stock in a stochastic economy is larger than $K(\rho)$, it is typically both because income is uncertain and because income is volatile. Ascribing all the difference between $K\left(r^{*}\right)$ and $K(\rho)$ to precautionary savings is therefore often misleading. Furthermore, when $\bar{r}<\rho$, borrowing constraints bind for some households in the equilibrium without uncertainty. Saying that binding borrowing constraints imply that there is positive precautionary savings is therefore also misleading.

I propose two alternative measures of aggregate precautionary savings in this framework. Given the above analysis of aggregate savings in the absence of income uncertainty, the first measure follows naturally as $K\left(r^{*}\right)-K(\bar{r})$, i.e. the difference between the capital stock in the economies with and without uncertainty. A possible problem with this measure is that households perfectly foresee volatile income paths in the economy without uncertainty. This information structure is not necessarily the natural benchmark to be compared to the stochastic economy. The second measure of precautionary savings is the difference between the capital stock in the stochastic economy and the capital stock in an economy with certainty equivalent behavior as described in Section 2.3. This measure is then $K\left(r^{*}\right)-K(\hat{r})$.

Table 3 reports aggregate precautionary savings according to these two measures and relates precautionary savings to the equilibrium capital stock when income is constant, so that $r=\rho$ in equilibrium. The last columns in Table 3 show that precautionary savings explain between 12 and 69 percent of the increase in aggregate capital above $K(\rho)$ 
according to the first measure, and between 56 and 88 percent according to the second measure. When risk aversion (and prudence, see Kimball 1990) is low or modest most of the additional capital accumulation is explained by income volatility and permanentincome motives rather than precautionary motives.

Table 3: Aggregate Precautionary Savings

\begin{tabular}{|c|c|c|c|c|c|c|c|}
\hline \multirow[b]{2}{*}{$\gamma$} & \multirow[b]{2}{*}{$\sigma^{2}$} & \multirow[b]{2}{*}{$\mu$} & \multicolumn{3}{|c|}{$K\left(r^{*}\right)-$} & \multirow[b]{2}{*}{$\frac{K\left(r^{*}\right)-K(\bar{r})}{K\left(r^{*}\right)-K(\rho)}$} & \multirow[b]{2}{*}{$\frac{K\left(r^{*}\right)-K(\hat{r})}{K\left(r^{*}\right)-K(\rho)}$} \\
\hline & & & $K(\bar{r})$ & $K(\hat{r})$ & $K(\rho)$ & & \\
\hline \multirow[t]{3}{*}{0.98} & 0.020 & 1 & 0.09 & 0.45 & 0.77 & 0.12 & 0.59 \\
\hline & & 3 & 3.20 & 4.61 & 5.68 & 0.56 & 0.81 \\
\hline & & 5 & 11.25 & 14.28 & 16.29 & 0.69 & 0.88 \\
\hline \multirow[t]{3}{*}{0.95} & 0.030 & 1 & 0.35 & 0.55 & 1.00 & 0.35 & 0.56 \\
\hline & & 3 & 3.06 & 3.87 & 5.19 & 0.59 & 0.75 \\
\hline & & 5 & 7.29 & 8.89 & 11.09 & 0.66 & 0.80 \\
\hline
\end{tabular}

\section{Conclusion}

There are a number of reasons why households save and accumulate wealth. One reason is to smooth consumption. According to the permanent-income hypothesis, households therefore save in periods with unusually high income. Another reason is to accumulate a precautionary savings buffer if future income is uncertain. The permanent-income and precautionary motives for saving often go hand in hand since when income is uncertain, it is typically also volatile. Previous work studying aggregate precautionary saving in stochastic dynamic general equilibrium models has often disregarded this connection and calculated precautionary saving as the difference between the equilibrium capital stock and the capital stock implied by constant income. This paper has shown that in economies with realistic stochastic income processes, much of the additional capital accumulation is generated by permanent-income motives rather than precautionary motives. 


\section{Appendix A Solving the Deterministic Economy}

The economy is populated by a continuum of infinitely lived households that know their future income path. As an approximation, let the economy be populated by $N$ households, and assume that these households know that their productivity path is represented by a finite path $\left\{x_{t}\right\}_{t=0}^{T-1}$ such that $z_{t}=x_{t \bmod T}$ for $t \geq 0$. To generate the sequences $\left\{x_{t}\right\}_{0}^{T-1}$, I first draw $N$ independent values $x_{-1}$ from the ergodic distribution of $z$. I then generate random sequences $\left\{x_{t}\right\}_{t=0}^{T-1}$ for each household by simulating the $N$ independent Markov processes for $z$,using $x_{-1}$ as the initial values.

\section{Appendix A.1 Solution When $r=\rho$}

Let us first examine if an equilibrium with $r=\rho$ and no binding liquidity constraints can be supported. The aggregate capital stock is

$$
K=\left(\frac{\theta}{\rho+\delta}\right)^{\frac{1}{1-\theta}} .
$$

and the wage rate per efficiency unit of labor supply is $w=(1-\theta) K^{\theta}$.

Households solve

$$
\max \sum_{t=0}^{\infty}(1+\rho)^{-t} u\left(c_{t}\right)
$$

subject to

$$
a_{t+1}=(1+r) a_{t}+w z_{t}-c_{t},
$$

$z_{t}=x_{t \bmod T}, a_{0}=0$, and a household-specific sequence $\left\{x_{t}\right\}_{t=0}^{T-1}$.

Let

$$
\begin{gathered}
W_{t}=\sum_{j=0}^{\infty}(1+r)^{-j} w z_{t+j}, \\
\bar{W}=\sup _{0 \leq t<T} W_{t},
\end{gathered}
$$

and

$$
t^{*}=\arg \sup _{0 \leq t<T} W_{t} .
$$

Note that $W_{t}=W_{t \bmod T}$ for all $t$. Calculating $W_{t}$ is therefore straightforward, and $\bar{W}=$ $\sup _{t \geq 0} W_{t}$. After $T$ periods this economy has converged to the stationary equilibrium where each household's consumption is constant and equal to the annuity value $\bar{W}$. Moreover, household asset holdings cycles between zero and some higher value. More precisely, $a_{t}=0$ if $t \bmod T=t^{*}$ (Ljungqvist and Sargent, 2004, chapter 16.3.1), and $a_{t}$ at other dates can be calculated from the household's budget constraint. Finally, aggregate asset holdings $A$ is calculated as

$$
A=\frac{1}{N} \sum_{i=1}^{N} a_{t}^{i}
$$


where $a_{t}^{i}$ denotes the asset holdings of household $i$ at date $t$, and where $t$ is any date $t \geq T$. In practice I calculate

$$
A=\frac{1}{T N} \sum_{t=T}^{2 T-1} \sum_{i=1}^{N} a_{t}^{i}
$$

Note that the results in Table 1 and Figure 1 show that aggregate savings do not stabilize until the cycle length is very long. In the numerical calculations households do not care about the distant future. Typical computer precision is $10^{-16} \approx(1+\rho)^{-939}$ ) so that income 940 years away is neglected in the calculations. Using the theoretical result that consumption converges to $c=\rho \bar{W} /(1+\rho)$ will therefore result in an inaccurate asset path. To avoid such precision errors, I recalculate the consumption level every 100 periods. In these updates, consumption changes by less than $10^{-14}$. We know that with $a_{0}=0$, consumption is chosen so that $a_{T}=0$, and I check that the implied $\left|a_{T}\right|<10^{-10}$.

\section{Appendix A.2 Solution When $\mathbf{r}<\rho$}

If $r<\rho$, the return on savings is lower than the discount rate. Households therefore minimize on asset holdings and assets are depleted at least once in a sequence of $T$ periods in a stationary equilibrium. We look for the equilibrium interest rate $r$ such that $K(r)=$ $\int a \mathrm{~d} \lambda$ in a stationary equilibrium.

To find a period $s \in\{0,1, \ldots, T-1\}$ where $a_{s}=0$ in the stationary equilibrium, I follow this algorithm:

1. Guess that $s=0$.

2. Let $p=s$ and $k=T$.

3. Disregard liquidity constraints and solve

$$
\max \sum_{t=p}^{p+k-1}(1+\rho)^{-t} u\left(c_{t}\right)
$$

subject to

$$
\sum_{t=p}^{p+k-1}(1+r)^{-(t-p)}\left(c_{t}-w z_{t}\right)=0
$$

Note that we must specify a utility function before we can solve this problem. With CRRA utility, $u(c)=c^{1-\mu} /(1-\mu)$, and letting $\beta=(1+\rho)^{-1}$ denote the time discount factor, we get $c_{t+1}=[\beta(1+r)]^{\frac{1}{\mu}} c_{t}$ if the liquidity constraint does not bind in period $t$. Consequently

$$
\sum_{t=0}^{T-1}(1+r)^{-t} c_{t}=c_{0} \sum_{t=0}^{T-1}\left[\beta^{\frac{1}{\mu}}(1+r)^{\frac{1}{\mu}-1}\right]^{t}=c_{0} \frac{1-\left[\beta^{\frac{1}{\mu}}(1+r)^{\frac{1}{\mu}-1}\right]^{T}}{1-\beta^{\frac{1}{\mu}}(1+r)^{\frac{1}{\mu}-1}} .
$$


4. Calculate the implied asset path $\left\{a_{t}\right\}_{t=p+1}^{p+k}$. If any $a_{t}<0$, let $k=k-1$ and repeat from 3 .

5. If $p+k<s+T$, let $p=p+k$ and repeat from 3 .

6. If the implied $a_{s+T}>0$, let $s=s+1$ and repeat from 2. Otherwise we have found an $s$ such that $a_{s}=0$ in the stationary equilibrium.

After having found the asset paths $\left\{a_{t}^{i}\right\}_{t=0}^{T-1}$ for all $N$ households, calculate $\frac{1}{N} \sum a_{0}^{i}$ or $\frac{1}{T N} \sum_{t=0}^{T-1} \sum_{i=1}^{N} a_{t}^{i}$ and compare to $K(r)$. If aggregate asset holdings differ from the aggregate capital stock, update the guess for the interest rate and start over.

The algorithm here shows that solving the problem when $r<\rho$ is more complicated than when $r=\rho$. With $r=\rho$ the computation time is manageable even when $N=10,000$ households and $T=100,000$ time periods. When $r<\rho$ the computation time grows fast in $T$ and already when $N=2,000$ households and $T=1,000$ time periods it is almost unmanageable. As long as $\bar{r}$ is much smaller than $\rho$ aggregate savings converge for small $T$. The solutions I report in Table 2 use $N=2,000$ and $T=500$ but the results do not change when I raise $T$. For the least persistent and volatile process $(\gamma=0.60$ and $\sigma^{2}=0.013$ ), however, the equilibrium interest rate $\bar{r}$ is close to the time preference rate $\rho$ and aggregate savings do not converge for small $T$. Consequently I have not been able to compute the equilibria for that process.

\section{Appendix A.3 Solution When Income Is Stochastic}

The solution algorithm follows Aiyagari (1994). I use the same approximation of the income process as above, i.e. I use Tauchen's (1986) algorithm with 9 states. I use a grid with 200 nodes for asset holdings. These nodes are unevenly spaced between zero and 50 times the aggregate capital stock implied by the (guessed) interest rate. Then I linearize the decision rule for consumption between the nodes and iterate on the Euler equation. When the decision rule has converged, I simulate the evolution of 2,000 households during 1,200 time periods, discard the initial 200 periods, and calculate the implied aggregate asset holdings based on the remaining observations. If aggregate asset holdings do not equal the capital stock, the guess for the interest rate is updated and the algorithm is repeated. 


\section{References}

Aiyagari, S. Rao (1994), "Uninsured Idiosyncratic Risk and Aggregate Saving", Quarterly Journal of Economics, 109, 659-684

Chamberlain, Gary and Charles A. Wilson (2000), "Optimal Intertemporal Consumption under Uncertainty", Review of Economic Dynamics, 3, 365-395

Hubbard, R. Glenn, Jonathan Skinner, and Stephen P. Zeldes (1995), "Precautionary Saving and Social Insurance", Journal of Political Economy, 103, 360-399

Huggett, Mark (1993), "The Risk-Free Rate in Heterogenous-Agent Incomplete-Insurance Economies", Journal of Economic Dynamics and Control, 17, 953-969

Huggett, Mark, and Sandra Ospina (2001), "Aggregate Precautionary Savings: When Is the Third Derivative Irrelevant?", Journal of Monetary Economics, 48, 373-396

Kimball, Miles S. (1990), "Precautionary Saving in the Small and in the Large", Econometrica, 58, 53-73

Leland, Hayne E. (1968), "Saving and Uncertainty: The Precautionary Demand for Saving", Quarterly Journal of Economics, 82, 465-473

Ljungqvist, Lars, and Thomas J. Sargent (2004), Recursive Macroeconomic Theory, Second Edition, MIT Press

Lukacs, Eugene (1975), Stochastic Convergence, Second Edition, Academic Press

Sandmo, Agnar (1970), "The Effect of Uncertainty on Saving Decisions", Review of Economic Studies, 109, 353-360

Storesletten, Kjetil, Chris I. Telmer, and Amir Yaron (2000), "Consumption and Risk Sharing over the Life Cycle", NBER Working Paper No. 7995

Tauchen, George (1986), "Finite State Markov-Chain Approximations to Univariate and Vector Autoregressions", Economics Letters 20, 177-181 